\title{
A polis e seus outros: os metecos atenienses e a historiografia sobre a polis*
}

\author{
Fábio Augusto Morales* *
}

MORALES, F.A. A polis e seus outros: os metecos atenienses e a historiografia sobre a polis. Revista do Museu de Arqueologia e Etnologia, São Paulo, 18: 183-197, 2008.

Resumo: Este artigo discute o problema da construção historiográfica do conceito de polis, utilizando como estratégia a análise do tratamento historiográfico ao tema da inclusão/exclusão dos estrangeiros residentes (metecos) na polis ateniense clássica. São propostos seis modelos: a cidade religiosa, a cidade consumidoraestamental, a cidade moderna, a cidade de classes, a cidade institucional e a cidade filosófico-existencial; após isto, o artigo discute algumas alternativas historiográficas recentes.

Palavras-chave: Historiografia - Modelos - Atenas - Metecos.

\section{As poleis de Aristóteles}

乙 á pelo menos um século e meio, a

1 polis tem sido a categoria central nos estudos historiográficos sobre a chamada "Grécia Antiga" (Guarinello 2003; Vlassopoulos 2007). Mas o que é uma polis? Antes de passarmos em revista alguns dos diversos modelos historiográficos da polis, comecemos com uma das principais fontes para estes modelos, escrita por um conhecido meteco ateniense do século IV a.C. - Aristóteles.

Para o estudioso da natureza do governo [politeia], do que é cada uma de suas formas e de quantas elas são, a primeira pergunta a fazer se refere à polis: que é uma polis? Até hoje esta é

$\left({ }^{*}\right)$ Pesquisa de mestrado financiada pela FAPESP, sob orientação do Prof. Dr. Norberto Luiz Guarinello. $\left.{ }^{(* *}\right)$ Mestrando em História Social pela Faculdade de Filosofia, Letras e Ciências Humanas, Universidade de São Paulo (fabiomorales@usp.br). uma questão controvertida; algumas pessoas dizem que a polis pratica um ato, outras que não é a polis, mas a oligarquia ou a tirania no poder; vemos que a atividade do estadista e do legislador tem por objeto a polis, e uma constituição é a forma de organização dos habitantes de uma polis [ton ten polin oikounton]. Mas a polis é um complexo, no mesmo sentido de quaisquer outras coisas que são um todo mas se compõem de muitas partes; é claro, portanto, que devemos primeiro investigar a natureza do cidadão, pois uma polis é uma multidão de cidadãos [he gar polis politon ti plethos estin], e portanto se deve perguntar quem deveria ser chamado de cidadão, e o que é um cidadão [tis ho polites esti]. (Política, 1275a) ${ }^{1}$

(1) A tradução utilizada, com adaptações, é a de Mario da Gama Kury (Aristóteles 1997). 
"A polis é uma multidão de cidadãos": esta definição se tornou o lema da historiografia da polis, que acabou por identificar a "História das poleis gregas" com a "História dos cidadãos gregos". No entanto, esta é apenas uma das definições apresentadas por Aristóteles: a caracterização desta questão como "controvertida" pelo autor da Política indica tanto a polissemia do termo, quanto a introdução da obra dentro de um debate já estabelecido, formando o que viria a ser a "teoria política" como estudo da "natureza do governo", da "constituição da cidade", politeia. Neste debate, conforme Aristóteles, algumas definições são formuladas: a polis como "sujeito" de uma ação; a polis como "objeto" da ação do estadista ou legislador; a polis como espaço de moradia de habitantes organizados de acordo com uma constituição; a polis como categoria de análise (um todo formado por partes); e por fim, a polis como uma multidão de cidadãos. Ainda que as definições anteriores, embora não aceitas por Aristóteles, indicassem caminhos de pesquisa extremamente interessantes, a historiografia se contentou com a última, promovendo assim, automaticamente, a exclusão historiográfica dos não-cidadãos (mulheres, crianças, estrangeiros, escravos) da História da polis - os não-cidadãos são mencionados apenas para que suas exclusões e inclusões na polis sejam listadas: proibidos de sentar à Assembléia, podem participar de certos rituais religiosos; excluídos do acesso à propriedade de terra, podem exercer atividades militares ao lado dos cidadãos etc.

Entretanto, o próprio texto de Aristóteles acima citado oferece alternativas. A "polis dos habitantes" indicada coloca a possibilidade de se pensar a polis para além da multidão de cidadãos, situando o conceito de polis justamente dentro do movimento das relações sociais entre habitantes, cidadãos e não-cidadãos. Além disso, a "polis como sujeito" e a "polis como objeto" nos trazem questões como a relação entre Estado e sociedade e da polis como obra social: qual é a natureza da polis que a permite conjugar aspectos subjetivos e objetivos? Quem faz parte, afinal, da construção da subjetividade/objetividade da polis?

Vemos, portanto, que a discussão aristotélica sobre a polis e mesmo sua restrição à "multidão de cidadãos”, longe de fechar o conceito de polis como idêntica aos cidadãos, vai na direção de abrir possibilidades para o estudo da polis que leve em conta as relações sociais entre os habitantes. Assim, as três primeiras definições mencionadas acima (polis como sujeito, polis como objeto, e polis como espaço dos habitantes) podem recolocar de um modo diferente a quarta definição, da polis como "um todo formado por partes", ou seja, pensar a polis como um todo marcado por contradições entre partes nãohomogêneas, como entre proprietários/nãoproprietários, livres/escravos, homens/mulheres, nativos/estrangeiros. $\mathrm{O}$ estudo do modo de articulação destas contradições dentro da polis permitiria, inclusive, repensar o conceito de política e de cidadania para além da "multidão de cidadãos".

Não foi este o caminho seguido, entretanto, pela historiografia da polis constituída na Europa e Estados Unidos nos séculos XIX e XX.

\section{Seis modelos de polis em relação aos metecos}

A proposta do presente texto é realizar um balanço dos modelos historiográficos construídos para o estudo da polis, realizando uma crítica da identificação polis-"multidão de cidadãos" nos vários modelos e apontando algumas alternativas de análise que surgiram no final do século XX e início do XXI. A estratégia adotada para tal projeto é pensar como a historiografia tratou a questão da inserção dos estrangeiros residentes $(\text { metecos })^{2}$ na sociedade ateniense, e isto por duas razões principais: em primeiro lugar, como bem anotado pela historiografia, os estudos de História da Grécia se baseiam, sobretudo, na História de Atenas, constituindo o chamado "atenocentrismo" (Mossé 1995), o que faz com que a crítica do tratamento do tema da polis, particularmente Atenas, seja uma via para se

(2) A tradução do termo grego metoikos é bastante discutida. Geralmente entendido como "aquele que mora junto", a palavra deriva de meta, que pode ser utilizado como "junto de", "que veio de", "posto em"; e oikos, "casa, moradia". Whitehead (1977) defende que o sentido de metoikos incorpora o conceito de mudança, migração. 
alcançar as lógicas que fundam os esquemas explicativos da História da Grécia atenocêntrica; ${ }^{3}$ em segundo lugar, atentar para o tratamento dado à questão do estrangeiro residente na polis é um modo de perceber, nas fronteiras dos modelos, os seus próprios limites teóricos - o tratamento dado ao "outro interno" da polis indica também a imagem do "si mesmo" do modelo.

Os modelos propostos não correspondem sempre a projetos conscientes dos autores agrupados: trata-se, muito mais, de elementos característicos em cada obra que permitem a identificação de certas semelhanças, sem que necessariamente tenham existido ligações intelectuais ou nacionais entre os autores. Além disso, a presente proposição é uma tentativa de superar as dicotomias econômicas entre primitivistas e modernistas (Will 1954) ou sociológicas entre durkheimianos e weberianos (Murray 1990), posto que a multiplicidade da historiografia vai além destas oposições. Os critérios adotados para a definição dos modelos serão especialmente a lógica de apresentação da história da polis e quais aspectos são enfatizados e quais são negligenciados como núcleos explicativos, de acordo com as teorias que os informam; elementos secundários de certos modelos podem estar presentes em outros, mas o esforço se concentrará em definir o elemento determinante em cada modelo.

Serão aqui propostos seis modelos de polis, ou seguindo a tradição, seis modelos de "cidade", pelos quais a historiografia pensou a questão dos metecos atenienses, analisados a partir das obras de seus principais autores: a cidade religiosa de Fustel de Coulanges e F. de Polignac; a cidade consumidora-estamental de M. Weber e M.

(3) $O$ que não significa, de modo algum, que aqui se proponha uma nova "História da Grécia": "Grécia" é uma construção histórica, não ontológica, e, portanto, os espaços considerados "gregos" variaram no tempo. Para uma crítica da "História da Grécia", cf. Hall (1998) e Guarinello (2003); uma nova proposta, mas que ainda reifica a "Grécia", além de se valer da "metanarrativa" de Hayden White de um modo acrítico, está em Vlassopoulos (2007: 221-240).
Finley; a cidade moderna de E. Meyer, M. Rostovtzeff, E. Cohen e K. Vlassopoulos; a cidade de classes de S. Utchenko, G. de Ste. Croix e E. Wood; a cidade institucional de G. Glotz e M. Hansen; e a cidade filosófica-existencial de J.-P. Vernant e Ch. Meier.

\section{A cidade religiosa}

Neste modelo, a religião é núcleo do esquema explicativo: a polis é acima de tudo uma comunidade de culto. O fundador do modelo é Fustel de Coulanges, que, na sua clássica A Cidade Antiga, de 1863, se inseria nos debates sociais e políticos do XIX afirmando que, diferentemente dos modernos (cuja sociedade se fundava no trabalho e na liberdade individual), entre os antigos a propriedade privada tinha origem no culto familiar e a liberdade individual era suprimida diante da onipotência do Estado. O modelo ganhou novo impulso com o estudo do também historiador francês F. de Polignac La naissance de la cité grecque, de 1984, que, inserido na revolução epistemológica que ocorria no campo da arqueologia, analisa o nascimento da polis por meio da instituição de santuários rurais e urbanos e cultos específicos, que, representando os limites entre natureza/cultura e eu/outro, realizariam a definição do território e a identidade cívica da polis.

Qual seria o lugar do estrangeiro residente na cidade religiosa? Se a cidade é o espaço sagrado dos cidadãos, ao estrangeiro cabe o papel de sacrílego. Nas palavras de Fustel de Coulanges:

"O estrangeiro é aquele que não tem acesso ao culto, a quem os deuses da cidade não protegem e que nem sequer possui o direito de invocá-los. Estes deuses nacionais, como só querem receber orações e oferendas do cidadão, repelem todo homem estrangeiro: a entrada do estrangeiro nos templos não é permitida e sua presença durante as cerimônias é um sacrilégio. [...] Desta forma, a religião abria entre o cidadão e o estrangeiro uma distinção profunda e indelével" (Fustel de Coulanges 1995: 204-5). 
Na obra de F. de Polignac, o estrangeiro residente aparece somente com a colonização, na forma de população conquistada: os sujeitos históricos são os fundadores, da cidade e dos cultos; os não-cidadãos são meros objetos diante da ação colonizadora, aparecendo na forma de trabalhadores submetidos ou esposas dos colonos.

Mas fica a questão: como interpretar a inserção de cultos propriamente estrangeiros na polis, ou mesmo a permissão aos metecos de participarem de determinados cultos cívicos? (Clerc 1893). Segundo o modelo, seria absurdo. De todo modo, sendo a religião cívica o núcleo da definição da cidade, e na medida em que o estrangeiro estava excluído do culto cívico, ele também estará excluído da narrativa historiográfica.

\section{Cidade consumidora-estamental}

Este modelo de cidade deriva da abordagem primitivista-substantivista da economia antiga (Carvalho 2007), que enfatiza as diferenças entre a economia antiga e a moderna. As origens desta abordagem estão nas análises dos economistas alemães Karl Rodbertus e Karl Bücher, que caracterizavam, no final do século XIX, a economia antiga como "economia do oikos" (Rodbertus) e "economia doméstica fechada" (Bücher): a ausência de comércio e de trabalho livre seriam suas principais características. Contra esta leitura da economia antiga, se levantaram alguns historiadores, como o alemão E. Meyer, dando início à oposição primitivistas/ modernistas (Will 1954): enquanto modernistas (cujo modelo, a "cidade industrial-financeira", será analisado a seguir) defendiam que, em determinados períodos, as sociedades da Antiguidade apresentaram formações econômicas próximas das modernas (ou seja, economia industrial européia do final do século XIX e início do XX), os "primitivistas" argumentavam que existia uma diferença fundamental entre as sociedades antigas e modernas, a saber, que nas sociedades antigas a economia não havia se desenvolvido livremente (ou seja, tornando-se autônoma em relação ao conjunto da sociedade) como nas sociedades modernas, o que impediria, conseqüentemente, a caracterização das socieda- des antigas como "capitalistas" ou das cidades antigas como "pólos produtores".

Entre os autores mais representativos do modelo primitivista estão o sociólogo alemão M. Weber, especialmente em seu texto Tipologia das Cidades, escrito entre 1911 e 1913 e incluído na coletânea póstuma Economia e Sociedade (1999), e o historiador estadounidense M. Finley, em sua obra a A Economia Antiga (1986), publicada originalmente em 1973. Inserido na própria constituição científica da sociologia, M. Weber, em texto marcado pelo monumental esforço de construção de tipos ideais de cidade (a cidade consumidora, produtora, camponesa, comercial, oriental, árabe, ocidental-antiga, ocidental-medieval etc.), caracterizava a cidade antiga, entre outros elementos, pela ausência de um capitalismo livre e economicamente racional, pois reinava um capitalismo politicamente orientado tanto devido à centralidade da guerra, quanto ao caráter de consumidores dos cidadãos que eram, em si mesmos, proprietários de terra com residência urbana, além da importância social da organização estamental, limitando alguns ofícios para certos estamentos. M. Finley radicaliza a idéia weberiana de "cidade de consumidores" e afirma que devido à ausência de mercados (de trabalho, de exportação, de moeda, de investimentos) e de uma mentalidade aquisitiva por parte das elites, não é possível nem falar em uma "economia antiga"; mais importante do que a posição do indivíduo na estrutura produtiva da sociedade (que, segundo Finley, definiam as classes), era a posição do indivíduo no "espectro de status", que associava prestígio pessoal, ofícios e ordens sociais. ${ }^{4}$

Como os metecos atenienses se inserem neste modelo? Eles são os homo oeconomicus que os cidadãos, por questões estamentais e de prestígio, não poderiam ser. Nas palavras de Finley,

(4) Em obra posterior (Finley 1985), A Politica no Mundo Antigo, publicada originalmente em 1983, o autor retornará à noção de "classe social", elemento fundamental de sua explicação da estabilidade política das cidades expansionistas a partir, justamente, da idéia de conflito. Para uma crítica do "finleynianismo econômico”, cf. Joly (1999) e Vlassopoulos (2007: 123-42). 
"Por que razão Atenas, que elaborou grande número de leis com fortes penalidades para assegurar o fornecimento de cereais importados, vitais para sua subsistência, não legislou sobre quem poderia ocupar-se do comércio de cereais, grande parte do qual estava entregue a não-atenienses? [...] A elite possuía os recursos e o poder político e podia também comandar um vasto pessoal. Faltava-lhe a vontade, quer dizer, como grupo (quaisquer que tenham sido as reações de uma minoria) estavam inibidos por valores fundamentais. É decisivo notar que a denúncia habitual dos libertos e metecos, desde Platão até Juvenal, o tema invariável é moral e não econômico. Eram condenados pelos seus vícios e maus costumes e nunca como rivais que roubavam a homens honestos um modo de ganhar a vida" (Finley 1986: 80, grifo meu).

Desta maneira, o modelo da cidade consumidora-estamental reduz a subjetividade histórica dos metecos à atividade econômica que os cidadãos não querem (ou não podem) exercer. Mas como se inserem os metecos no espectro de status finleyniano? Não compartilhariam os metecos de Atenas da ideologia anti-econômica da elite; ou seriam eles portadores de uma racionalidade econômica avant la lettre? Ou ainda: quais são as possibilidades de uma ação econômica independente de interferência de estamento ou status, num contexto no qual a economia não se tornou autônoma em relação à sociedade? Ora, a explicação se restringe à visão cívica sobre os metecos (condenação moral, nãoeconômica), mas não se questiona sobre a natureza econômica da cidade a partir do ponto de vista dos metecos.

\section{Cidade moderna}

Este modelo é o núcleo da explicação "modernista" ou "modernizante" acima citada. Este modelo tende a explicar as transformações históricas em termos de motivações econômicas e comerciais, enfatizando nas análises as atividades produtivas da polis (contra a "cidade consumidora" dos primitivistas) e a articulação de mercados internacionais, atravessados por uma racionalidade econômica. Um de seus principais autores é $\mathrm{E}$. Meyer, em seu A Evolução Econômica da Antiguidade (1955), texto marcado pela crítica às análises de Bücher, e que ressalta o desenvolvimento de um mercado mundial a partir do século VII a. C. e a constituição de uma política econômica do Estado ateniense voltada para a formação de um império comercial-marítimo, fundando um regime burguês que aliava industriais, comerciantes, marinheiros, artífices e camponeses. Um dos seguidores das análises de E. Meyer foi o historiador russo M. Rostovtzeff, em seu História da Grécia (1973), publicado em 1925, que interpretava a democracia como fruto de uma luta pelo poder econômico e político entre burguesia e proletariado, com a vitória dos últimos e as conseqüentes tentativas de nivelamento não somente das riquezas, como também da inteligência, aos níveis mais baixos do povo - vale lembrar que o autor emigrou da Rússia revolucionária de 1917. Depois de um longo período de descrédito (ao lado da hegemonia primitivista), o modelo foi retomado recentemente por dois autores: o historiador estadounidense E. Cohen, em seu livro The Athenian Nation, de 2000, e pelo historiador grego Kostas Vlassopoulos, em seu livro Unthinking the Greek Polis, de 2007. E. Cohen, que, além da polêmica defesa de que Atenas é melhor caracterizada como uma nação (no sentido moderno e no antigo, de ethnos), argumenta que a economia ateniense integrava, por meio do mercado de trabalho, os habitantes da cidade independentemente das diferenciações estamentais: daí as análises dos escravos e libertos banqueiros, ou das cidadãs prostitutas; as instituições políticas atenienses aparecem no texto apenas para serem negadas diante da livre iniciativa dos oikoi, numa espécie de "neoliberalismo antigo". K. Vlassopoulos busca uma nova narrativa da História da Grécia, reabilitando o modelo modernista pela via das discussões do "sistema-mundo" de I. Wallerstein (1974) e da "história no e do Mediterrâneo" de P. Horden e N. Purcell (2000); ainda que o autor contribua intensamente para o debate, $\mathrm{O}$ autor menospreza os aspectos propriamente 
institucionais das poleis, diluindo as relações sociais nos "fluxos" de bens, pessoas e idéias.

Apesar das variações, o modelo incorpora o meteco dentro do contexto da expansão econômica de Atenas, que atraía os estrangeiros não devido às proibições estamentais dos cidadãos ao trabalho, mas sim ao crescimento exagerado da economia. Nas palavras de M. Rostovtzeff

"Durante este século [V a. C], as duas classes sem direitos civis, os metecos ou estrangeiros residentes e os escravos, aumentaram gradativamente em número e se tornaram mais proeminentes na vida social. A primeira classe foi deliberadamente atraída para a cidade pelos dirigentes políticos. Os próprios cidadãos estavam demasiado ocupados com a agricultura e com os assuntos públicos para darem muita atenção ao comércio e à manufatura. Portanto, os estrangeiros, que não tinham outra ocupação ou interesse a não ser os assuntos comerciais, tornaram-se o instrumento que, mais do que qualquer outra coisa, criou o extraordinário desenvolvimento econômico da Atenas desse século. [...] Isoladamente, não constituíam uma classe: em sociedade, não se fazia distinção entre um estrangeiro e um cidadão” (Rostovtzeff 1973: 179).

Ora, quanto à questão da inserção dos metecos na sociedade ateniense, pode-se observar que a cidade moderna não é tão diferente da cidade consumidora, seu oposto: enquanto os cidadãos fazem política, os metecos (junto dos escravos) são os atores econômicos - a diferença se situa somente na ideologia dos cidadãos. Ainda que existam referências a uma "proeminência social” dos não-cidadãos, estes são relegados, na análise, ao lugar de instrumentos da política econômica dos cidadãos - a própria centralidade da economia na explicação historiográfica acaba por excluir uma possível leitura da dimensão subjetiva da sociabilidade dos não-cidadãos.

\section{Cidade de classes}

O modelo da cidade de classes, de inspiração marxista, tende a enfatizar a pertinência dos conceitos de "classe social" e de "luta de classes" na explicação da história da sociedade ateniense. ${ }^{5}$ Embora K. Marx não tenha escrito nenhuma obra sistemática sobre a história da "cidade antiga” (greco-romana), este tema está presente em diversos momentos da obra marxiana, inserida em contextos variados, da tese de doutorado sobre Demócrito às análises das especificidades da produção mercantil desenvolvida n'O Capital. A ausência de uma análise sistemática realizada por Marx, aliada ao projeto de construção de uma ciência do materialismo histórico-dialético, deu impulso para que surgisse um debate sobre a polis no interior do marxismo, em suas várias correntes, separadas devido a interpretações divergentes sobre o que seria uma "teoria marxista da História”. No quadro das várias tensões que separam as diversas correntes marxistas, no campo do estudo da Antiguidade a principal divergência é a existência ou não do modo de produção escravista, e sua importância na determinação da estrutura e da luta de classes no mundo antigo. No caso específico ateniense, independentemente se os autores identificam ou não um modo de produção escravista, a luta de classes é centrada em uma luta entre ricos e pobres - exceto em eventos esporádicos (como a fuga dos escravos atenienses durante a Guerra do Peloponeso), a luta (possível) conduzida por escravos é descartada na análise.

Alguns dos principais autores da cidade de classes são: o historiador soviético S. Utchenko, o historiador inglês G. de Ste. Croix, e a historiadora estadunidense E. Wood. Escrevendo na década de 50, S. Utchenko, em seu Classes e estrutura de classes na sociedade escravagista antiga (1984) defende que havia duas lutas de classes na antiguidade, uma fundamental (senhor/escravo), outra acessória (rico/pobre), mas, na democra-

(5) "História da sociedade ateniense" e não "história da polis”, pois, de acordo com a interpretação do materialismo histórico predominante na tradição historiográfica, o núcleo da História se encontra nas relações sociais de produção específicas a cada sociedade, das quais se derivam as formas estatais. Por isso, serão analisados os conceitos de polis tais como aparecem tangencialmente nas obras dos autores marxistas analisados. 
cia ateniense, o desenvolvimento econômico tornava mais complexas as relações entre as classes, com conflitos que se sobrepunham à luta fundamental; infelizmente, o autor não desenvolve este argumento. Em uma das últimas defesas do "escravismo", G. de Ste. Croix, em seu The Class Struggle in the Ancient Greek World, de 1981, propõe que a economia antiga era escravista, pois as classes dominantes (definidas pelo ócio) extraíam seu mais-produto do trabalho escravo, ainda que este fosse insignificante na produção social total; os senhores dominavam o Estado, o que lhes permitia explorar, além dos escravos, os livres pobres exceto em Atenas, onde a democracia quebrou este monopólio e abriu a luta entre ricos e pobres; quanto aos escravos, o autor afirma que a luta era de mão-única, ou seja, somente de dominação dos senhores. Mais recentemente, E. Wood, em O trabalho e a democracia antiga e moderna (2003), texto escrito no final dos anos 1990, critica duramente a "teoria do escravismo antigo" relacionando-a menos com Marx do que com as ideologias elitistas do século XIX, e propõe alternativamente um modelo para a democracia ateniense como resultado da luta entre ricos e pobres pela propriedade politicamente constituída da terra, dando origem a um regime baseado na hegemonia dos cidadãoscamponeses - os escravos ocupariam um papel acessório nestas lutas.

A cidade de classes, diante dos metecos atenienses, encontrou-se perante um dilema: os metecos são uma classe ou um estamento? Sem conseguir definir os metecos como uma classe social distinta, além de não aceitar a validade explicativa do conceito (demasiadamente weberiano) de estamento, os metecos foram em geral deixados de lado na explicação. Nas palavras de Ste. Croix:

"Em um sentido, então, os cidadãos de um estado grego poderiam ser considerados uma classe distinta de proprietários de terra, [...] em contraposição aos estrangeiros, embora certamente eles mesmos estariam divididos em classes diferentes em confronto uma com a outra. [... contra aqueles que querem mais atenção aos metecos, o autor argumenta que] a maioria dos metecos que não eram libertos seriam cidadãos em outra polis, vivendo voluntariamente por um tempo em uma cidade que não a sua, provavelmente - exilados políticos ou não - com a intenção de retornar para casa no devido curso. E seguramente metecos não poderiam ser explorados intensivamente: se eles eram [metecos], eles simplesmente iriam para outro lugar" (Ste. Croix 1981: 289) [tradução minha].

Assim, mesmo que tenha dado indicações interessantes quando ao estatuto político da propriedade, assim como possíveis contradições sociais expressas na sociabilidade dos metecos, o modelo da cidade de classes não conseguiu incorporar os metecos na análise.

\section{Cidade Institucional}

Partindo da idéia de que existe uma separação entre sociedade e Estado, o modelo da cidade institucional tende a privilegiar a descrição das instituições políticas da polis (natureza, funções), utilizando como base uma história social de seu surgimento e transformações: inspirada na noção aristotélica de politeia (entendida como o conjunto, natureza e estrutura dos elementos institucionais da polis), a história da polis é a história da formação de sua politeia. Entre os principais autores do modelo estão G. Glotz e, atualmente, M. Hansen. O primeiro, historiador francês aluno de Fustel de Coulanges e provavelmente um dos historiadores mais influentes da primeira metade do século XX (Trabulsi 2001), em seu A Cidade Grega (1980), publicado na França em 1928, discute as contradições entre patriotismo e unificação na Grécia, além de simpatizar claramente com o modelo da democracia (segundo o autor) moderada de Atenas no século V a.C., por oposição ao arcaísmo espartano e ao individualismo ateniense do século IV a.C., debatendo portanto, indiretamente, com o nacionalismo alemão, o liberalismo e o socialismo. O segundo, historiador dinamarquês cuja obra se estende de estudos sobre os tribunais atenienses (1974) a 
um inventário das centenas de poleis gregas (Hansen \& Nielsen 2004), entrou em debates sobre a comparação entre a democracia antiga e moderna, criticando em particular, no mundo pós-Guerra Fria, a naturalização ideológica da democracia liberal como modelo único de democracia (1998); sua principal obra histórica individual, La démocratie athénienne à l'époque de Démosthène (1993), segue o padrão da discussão filológica e da descrição institucional.

Ainda que com diferentes discussões, ambos os autores dedicam centenas de páginas à descrição do funcionamento das instituições democráticas atenienses. Se G. Glotz faz uma historia social das instituições como harmonização dos conflitos, M. Hansen defende a importância dos arranjos institucionais como modeladores, inclusive, do modo de vida dos cidadãos. Os metecos atenienses entram no modelo da cidade institucional de três maneiras: a partir da listagem de suas exclusões/inclusões instituídas pelos cidadãos (não podem participar da Assembléia ou dos tribunais, não podem ter propriedade de terra, devem pagar um imposto especial, podem participar de determinados rituais religiosos, podem pagar liturgias etc.); também aparecem na sua inserção na vida econômica da cidade, que não é problematizada pelos autores; e, mais marginalmente, a partir da tentativa de burlar as imposições institucionais. Nas palavras de G. Glotz,

"Impunha-se preencher duas condições para ingressar na Ekklêsia: 1) era preciso ser ateniense, isto é, cidadão [...]. 2) era preciso ser maior [...]. O controle era facilmente efetuado: bastava consultar o pinax ekklêsiastikós, que era a cópia dos registros afixados nos dêmoi. Mas esses registros, por sua vez, não eram exatos. Os metecos conseguiam neles ser inscritos e, conseqüentemente, infiltrar-se na Assembléia. De nada servia lançar contra eles a terrível ação de estraneidade (graphê xênias) que tinha por resultado condenar o réu à escravidão; os 'mal inscritos' (hoi paréggraptoi) eram tão numerosos que se fazia necessário, de quando em quando, proceder a uma revisão geral das listas (diapsêphismós). Era raro a Assembléia estar composta, para empregarmos a expressão de Aristófanes, de 'farinha pura', sem 'farelos' de permeio" (Glotz 1980: 127).

Ora, aqui o autor traz elementos importantes para uma pesquisa sobre a dimensão propriamente política dos não-cidadãos: o que significavam estas tentativas de infiltração na Assembléia? Os metecos e escravos não eram simplesmente objetos da regulação institucional - como então contar a história de Atenas por meio de sua organização institucional, sem analisar a efetividade das instituições na prática social? Como o próprio autor afirma, raramente a Assembléia era composta apenas por cidadãos, ou seja, raramente a Assembléia funcionava como deveria funcionar: neste sentido, a história da polis ateniense pode se limitar à descrição do (raro) funcionamento institucional? O modelo da cidade institucional, ainda que ciosamente exclua os metecos da vida política ateniense, seguindo os regimentos, acaba por indicar, até pela própria existência da proibição, uma dimensão propriamente política da sociabilidade dos metecos atenienses.

\section{Cidade filosófico-existencial}

O modelo da cidade filosófico-existencial se caracteriza por, num projeto consciente de analisar as raízes do Ocidente, buscar uma explicação da originalidade grega na invenção da liberdade, da filosofia e da política, sem recorrer ao "milagre grego": o modelo propõe que o surgimento da polis teria criado um modo de ser específico, centrado na publicidade e laicidade da vida coletiva e na indissociação entre Estado e sociedade. $\mathrm{O}$ foco das análises é a história de Atenas, entendida como modelo por excelência de polis grega; podem-se integrar neste modelo duas linhas, a francesa e a alemã. Na primeira, destacase J.P. Vernant (1972), que bastante influenciado por seu professor L. Gernet (1968) e pelos debates entre marxismo, estruturalismo e psicologia social da França na segunda metade do século XX, propõe explicações totalizantes que integrassem a emergência do direito, da filosofia e da 
política grega a partir da história social da polis a existência de uma classe média teria tornado possivel um equilibrio social, base da existência da polis. Na linha alemã, destaca-se Ch. Meier (1995), que, escrevendo no último quarto do século XX, realiza um debate com as teorias neoliberais e de crise do Estado-nação afirmando que, ao contrário do mundo moderno, na Grécia Antiga existia uma dimensão da vida, o "político", que era autônoma em relação às outras dimensões sociais a ponto de não ser por elas determinado: a política era um "fim em si mesmo", o que garantiria, por meio da criação de uma identidade cívica plena, o exercício da liberdade coletiva - esta situação existencial do cidadão grego deu origem a uma nova concepção do tempo e do mundo, originando tanto a História quanto a Filosofia.

A história da polis, dentro deste modelo, é, portanto, a história dos cidadãos que exercem seus direitos políticos no espaço público da cidade, situação que trouxe os novos modos de ser no (e de pensar o) mundo. Qual o lugar dos metecos? Na medida em que o meteco não compartilha desta existência política, os metecos não fazem parte da polis para além de base econômica. Em J.-P. Vernant os metecos não são citados nenhuma vez em todo o livro, enquanto os não-cidadãos em geral são citados apenas em uma nota, ressaltando que "a igualdade [dos cidadãos] se esboça num fundo de desigualdade" (Vernant 1970: 47, n. 9). Ch. Meier ainda cita os metecos em uma ocasião, ressaltando que:

"Uma grande parte do trabalho era executada pelos não-cidadãos e escravos, e trabalho e política, casa e polis estavam portanto muito claramente separados. $\mathrm{O}$ pertencimento à categoria de cidadão portanto continuou o único verdadeiramente importante, mais importante que o pertencimento doméstico. [...]. É na Atenas do quinto século que a identidade política foi realizada do modo mais puro. Para os grandes grupos de cidadãos serem cidadãos (e soldados) era a principal atividade e a principal fonte de rendimentos. Aquilo não seria possível a não ser que uma grande parte da atividade econômica fosse realizada por metecos e escravos, os quais, assim como as cidades aliadas, estavam ali para permitir esta vida política". (Meier 1995: 179) [tradução minha].

O modelo da cidade filosófico-existencial, francesa e alemã, ao restringir a polis à comunidade de cidadãos, coloca os não-cidadãos em geral e os estrangeiros em particular em uma dimensão não-política, a saber, o mundo econômico. Mas fica a questão: o "universo espiritual" da polis (Vernant) ou o "modo político de ser" (Meier), que ultrapassam os aspectos institucionais da polis, não ultrapassariam também os limites estamentais da cidadania institucional? Não estariam também os nãocidadãos imersos também neste "universo espiritual"? Se sim, abre-se um imenso campo de pesquisa sobre as formas de ação política, possiveis e efetivas dos não-cidadãos. Se não, fica a lacuna sobre o modo de articulação entre o "mundo político" e o "mundo econômico", supondo-se que este realmente existiu de modo autônomo, questão que os autores do modelo não se fazem.

\section{Modelos alternativos recentes}

A partir da década de 90 começaram a surgir alguns modelos de cidade alternativos à "polis como comunidade e/ou Estado dos cidadãos", que buscam dar conta especialmente das questões de integração e sociabilidade que existiam entre os habitantes de Atenas, cidadãos e não-cidadãos. As tentativas de revisão de dois autores serão discutidas: a primeira, do historiador estadunidense Josiah Ober, procura relacionar, a partir de uma interpretação liberal (baseada no teórico John Rawls), uma "políticopolis", restrita aos cidadãos, com uma "geo-polis", que incluiria os habitantes de Atenas; a segunda, da historiadora brasileira Marta M. de Andrade, parte da construção de uma noção historicamente constituída de "cotidiano ateniense" (kath'oikian, vida comum ou doméstica) para uma história dos habitantes atenienses que ultrapassasse os controles ideológicos sobre as sociabilidades espaciais dos não-cidadãos. 
A primeira revisão analisada nasceu do debate entre o historiador estadounidense J. Ober e o historiador dinamarquês M. Hansen, acima citado, a respeito das relações entre Estado e Sociedade na Atenas Clássica e suas derivações conceituais. No texto The polis as a society: Aristotle, John Rawls, and the Athenian social contract (1996: 161-87), J. Ober se opõe à abordagem institucional de M. Hansen, propondo uma leitura que reúna, sob o conceito de polis, os dois significados de "sociedade como um todo", chamada pelo autor de geo-polis, e de "comunidade dos cidadãos", a político-polis (p. 167): esta duplicidade tanto abriria um modo de se pensar a polis em seu significado social, quanto ampliaria o estudo da política, não mais restrita às instituições, na direção da ideologia e da prática democrática.

Como se relacionam a politico-polis e a geo-polis em J. Ober? Ao contrário de Hansen, o autor interpreta o termo politeia em Aristóteles não do ponto de vista institucional, mas do ponto de vista sócio-contratual: para que as instituições funcionem, é preciso que os cidadãos e os não-cidadãos concordem, voluntariamente, em viver sob estas instituições (p. 175). A partir disto, e apoiando-se num paralelo entre Aristóteles e um teórico liberal do século XX, John Rawls, o autor afirma que, na "melhor das poleis", existiria um contrato social que garantiria, por meio das instituições, a liberdade política, a (aceitável e desejável) desigualdade econômica e a igualdade de oportunidades. Este arranjo era possivel, em Atenas, devido à articulação específica entre a dimensão pública e a dimensão privada da vida: enquanto a primeira era formalmente restrita aos cidadãos, a segunda, que englobava não só a casa, mas também a vida econômica, a educação, a religião etc., era aberta aos habitantes da polis, cidadãos e não-cidadãos a democracia ateniense seria estável, para o autor, 1) por garantir a liberdade política dos cidadãos, ricos ou pobres, e 2) por manter a desigualdade social em níveis aceitáveis, por meio da defesa da propriedade privada ao lado de medidas de redistribuição de riqueza, como liturgias, distribuição de trigo, festivais etc. (pp. 178-85).

No entanto, ainda fica a questão da relação entre a político-polis e a geo-polis, pois, se a garantia da estabilidade reside na conjugação da desigualdade econômica com a liberdade política, como se enquadram aqueles que são desiguais economicamente e que não têm liberdade política, ou seja, os não-cidadãos? Alguns caminhos são indicados: "Certas práticas e alterações do quarto século no procedimento legal podem ser lidas como a (tentativa e condicional) extensão de algumas liberdades básicas para alguns não-cidadãos" (p. 186, tradução minha), mas o próprio autor reconhece o quão vagas são estas indicações. Diante deste impasse, conclui que toda sua elaboração funcionalista e contratualista aborda apenas alguns aspectos da sociedade, mas que não pode oferecer "uma completa e satisfatória explanação do fenômeno da polis" - e termina, nas últimas linhas, por questionar (talvez não conscientemente) $\mathrm{o}$ próprio modelo: "Depois de pesar a sociedade ateniense nas escalas de justiça social, nós podemos ainda desejar celebrar os ideais da cidadania democrática e participativa; mas nós nos lembraremos das profundas e resistentes injustiças que caracterizaram mesmo a melhor das poleis" (p. 187, tradução minha). De qualquer maneira, J. Ober, na crítica à restrição da polis ao seu sentido estatal, institucional, contribui fortemente para uma reavaliação do conceito de polis.

Uma abordagem que não entra, ao menos diretamente, no debate Hansen-Ober, mas que contribui fortemente para um estudo da polis enquanto sociedade é apresentada no livro da historiadora brasileira M. de Andrade, A vida comum: espaço, cotidiano e cidade na Atenas Clássica (2002). Voltando-se para a história dos não-cidadãos da polis ateniense, em particular as mulheres, a autora constrói um modelo baseado na idéia de "vida cotidiana" como dimensão historicamente específica da vida social ateniense, e que conteria, não "cidadãos", mas "habitantes" da polis, especialmente no espaço urbano (fundamento da cotidianidade, no caso), onde as distinções estamentais (cidadãos/não-cidadãos) seriam postas em questão, para além das representações pacificadas destas relações na ideologia cívica. A "polis dos cidadãos", ou melhor, os modelos de cidade elaborados a partir do corpo cívico (especialmente Aristófanes e Platão), tomados 
como representações, são entendidos aqui no contexto de uma tentativa de controle deste espaço social cotidianamente apropriado pelos habitantes: daí a interpretação da comédia de Aristófanes e da teoria política de Platão, Xenofonte e Aristóteles, como propostas de identificação do espaço cívico com o espaço habitado, propostas estas que são indícios, para a autora, de que "as fórmulas anteriores, o discurso cívico, a perfeita identificação da comunidade política com o espaço da cidade [...] estavam perdendo a capacidade de equilibrar o privilégio da cidadania com as prerrogativas cotidianas dos cidadãos, nas interações sociais comuns" (p. 231). Esta crise, que, ressalta a autora, não é a "crise da polis", mas dos "modelos de ação coletiva fundados na cidadania como privilégio sobre a apropriação do espaço habitado” (p. 235), teve como manifestação a "estilização" e "politização" da vida cotidiana: na medida em que os cidadãos tiveram seus privilégios ameaçados no espaço da vida cotidiana, este último se tornou o palco de negociações e projetos de controle (presentes na comédia, na teoria política, na cerâmica etc.).

Com o estudo de M. de Andrade, pode-se dizer, está aberto um caminho para uma história do cotidiano na Atenas Clássica focando os habitantes e a cidade habitada, ultrapassando assim a barreira da polis dos cidadãos. Entretanto, esta polis aparece em todo o texto apenas como representação, como modelo, ideologia, projeto de controle: a materialidade da polis dos cidadãos, ou seja, os aspectos institucionais de regulação não apenas no campo das representações, mas também no campo das práticas, ou está ausente, ou aparece como pressuposto, mas mesmo assim não são desenvolvidos juntamente com os outros aspectos analisados. Pode-se entender esta ausência na medida em que a autora se debruça sobre as "representações de espaço e cotidiano", e deste modo, mesmo a polis enquanto instituição aparece apenas no campo das representações; de qualquer modo, fica a questão sobre as possibilidades de uma história da vida cotidiana (espacialmente concebida) como independente dos aspectos institucionais objetivos (e subjetivados) da polis dos cidadãos.

\section{Alguns apontamentos}

Após este longo percurso historiográfico, terminaremos este texto com algumas brevíssimas indicações que podem contribuir para a reorientação dos estudos sobre a polis, de modo a ultrapassar a "polis dos cidadãos" na direção de uma "polis dos habitantes", mas sem ao mesmo tempo excluir da análise a efetividade das instituições cívicas exclusivistas. Não se trata da formulação exaustiva de um modelo alternativo, mas de apenas alguns apontamentos realizados a partir da identificação dos limites e das possibilidades discutidos anteriormente na própria historiografia.

A polis como discurso. A palavra polis tinha múltiplos significados, mas tendia a cristalizar-se em dois, como apontou M. Hansen, a saber: comunidade de cidadãos e sociedade como um todo - nas palavras de J. Ober, político-polis e geo-polis. Longe de procurar colar os significados, imediatamente, à realidade social, podemos entender os significados de polis inseridos dentro de um espaço discursivo no qual os significados eram disputados, negociados (M. de Andrade), a partir de duas direções: a tentativa de um ordenamento cívico, que coloca a comunidade restritiva dos cidadãos como identificados inteiramente com a polis (base dos diversos modelos historiográficos analisados); e uma outra, tática, contra este ordenamento, que associava à polis o conjunto dos habitantes, cidadãos ou não. E na medida em que os não-cidadãos se associavam à polis, no nível do discurso, isto apresentava um risco para a própria identidade cívica.

A polis como instituição. Entretanto, a “polis dos cidadãos" não se limita a uma pura existência discursiva, mas possuía também uma materialidade institucional nas relações sociais, como mediação fundamental: era por meio das instituições da polis que se realizava a propriedade da terra, a defesa da polis como um todo pela guerra, a manutenção do aparelho jurídico da escravidão, a organização cívica dos cultos e procissões, dos festivais, entre outros elementos. K. Marx, na famosa passagem sobre a "cidade antiga" das 
Formen (Marx 1977: 70), analisa como o caráter simultâneo de pressuposto e resultado da ação social fazia com que a "cidade" (enquanto Estado) assumisse um caráter natural, ou ainda, "sobrenatural, divino". É possível interpretar esta naturalização das instituições estatais da polis como um processo de reificação (como objetivação, cristalização de práticas anteriores - trabalho morto social - no sentido da reprodução das estruturas comunitárias), que se apresenta de maneira diferente para cidadãos e nãocidadãos: aos cidadãos, as instituições tornam possível, por meio da prática política institucionalizada, uma identificação entre o sujeito cidadão e o objeto polis no sentido de uma desnaturalização, constituindo assim a identidade como apropriação; aos nãocidadãos, é vedada a participação institucional, constituindo assim um processo de alienação no qual a polis-cidadãos é o Outro dos nãocidadãos - entretanto, como aponta M. de Andrade, existiam espaços de prática social (o espaço doméstico, a vida cotidiana) na qual os não-cidadãos se apropriavam da polis, não apenas no nível do discurso, mas também no nível das práticas sociais.

A polis como sociedade. A partir do que foi dito, fica clara a necessidade de se reabrir o debate sobre a estrutura e a dinâmica da sociedade políade, da tradição inglesa e francesa (Finley 1986; Ste. Croix 1981; Mossé $\&$ Vidal-Naquet 1979), procurando formas de se superar as dicotomias entre "estamento e status" (nas abordagens primitivistas) e "classe social" (nas abordagens modernistas e marxistas) - trata-se de desvendar as lógicas específicas que atravessam os grupos sociais em suas relações com a institucionalidade e a cotidianidade da polis, entre estrutura e ação (Guarinello 2004). Ou seja, rediscutir os critérios de ordenamento social que permitem a transversalidade de categorizações diversas, de ordem jurídica (estamentos), econômica (classes), ético-moral (status) etc., a partir de suas imbricações na formação de uma determinada totalidade, e em que medida esta mesma transversalidade põe em cheque a própria totalidade. Trata-se, enfim, de recolocar o conflito e a contradição no centro do debate sobre a polis (Loraux 2005).

A polis como identidade. Uma das questões que podem ser agregadas a uma nova abordagem é a da negociação da identidade ateniense, não mais reificada em termos de cidadãospolítica, metecos-comércio, escravos-trabalho e mulheres-casa, mas inseridas no movimento mais amplo das relações sociais e suas contradições: pode-se observar, por exemplo, nos discursos judiciários do meteco ateniense Lísias (particularmente, Lys. xii), determinados procedimentos discursivos de deslocamento identitário, pelos quais os metecos passam a ser associados à democracia e à polis, não como homo oeconomicus, mas como sujeito participante. Esta abordagem, efetuada a partir de outras fontes (como, por exemplo, ler a Política de Aristóteles considerando que o autor viveu como meteco ateniense por cerca de quarenta anos), pode resultar em um novo quadro da sociedade políade ateniense. A religião e a guerra também ocupariam papeis importantes para uma rediscussão da "cidadania religiosa e militar", muito mais inclusiva que a "política-institucional", e quais suas conseqüências para a formulação de uma "identidade cívica" ateniense.

A polis como espaço. Além disso, como bem alertado pela historiografia mais recente (Andrade 2002: 33; Millett 1998), é preciso reespacializar a polis de modo a perceber as contradições entre apropriação e alienação nos próprios usos do espaço: continuando a polis uma mera abstração institucional, na qual os cidadãos pairam no ar, perde-se uma vasta gama de possibilidades de análise dos espaços de apropriação da cidade habitada pelos nãocidadãos, da "casa" a "regiões inteiras": neste sentido, as análises sobre o porto do Pireu, de intensa habitação dos metecos, (Garland 1987; von Reden 1995; Roy 1998), dos espaços e circuitos rurais (Chevitarese 2001) e das relações propriamente espaciais entre os vários demos (Osborne 2000) são etapas fundamentais na construção de uma maior complexidade no estudo da polis.

A polis como forma historiográfica. Finalmente, trata-se de relativizar profundamente 
as pretensões objetivantes tão comuns na historiografia de tendência empirista, que, sob a capa da (necessária) erudição, acaba por reproduzir teorias e pressupostos de modo nem sempre consciente. ${ }^{6}$ Neste sentido, torna-se fundamental o movimento hermenêutico de discussão da polis como discussão de si mesmo, alertando para os limites e para as possibilidades postos pelo próprio movimento da compreensão (Ricoeur 1990). Ora, a polis é parte da forma "História Antiga" (Guarinello 2003), e, portanto diz respeito tanto à complexidade, fragmentação e desordenamento da documentação (matériaprima da forma historiográfica), quanto ao tempo presente do historiador. Considerando que, como padrão, ainda se traduz polis como "cidade", "Estado" ou "cidade-estado", vale a pena a discussão sobre o significado destes termos hoje e quais são as possibilidades de tradução, no sentido historiográfico, das realidades sociais daquilo que denominamos polis para a linguagem do mundo contemporâneo. O termo "cidade" hoje ainda é equivalente ao Stadt weberiano? O que é uma cidade hoje? A ciência política e a geografia urbana, entre muitas outras disciplinas, certamente têm muito a contribuir para uma historiografia da polis que, de princípio, questione o si-mesmo como ponto de partida (e de chegada) da operação historiográfica.

\section{Agradecimentos}

Este texto é tributário dos extensos debates com o Prof. Dr. Norberto Luiz Guarinello. Agradeço também às críticas e sugestões das Prof ${ }^{\text {as }}$. Dr ${ }^{\text {as }}$. Maria Beatriz Borba Florenzano (MAE-USP) e Marta Mega de Andrade (UFRJ), além da leitura sempre crítica de Cynthia Aragão Oliveira.

MORALES, F.A. The polis and its others: the Athenian metics and the historiography about the polis. Revista do Museu de Arqueologia e Etnologia, São Paulo, 18: 183-197, 2008.

\begin{abstract}
This paper discusses the problem of the historiographical construction of the concept of polis, using as strategy the analysis of the historiographical treatment to the subject of the inclusion/exclusion of the resident aliens (metics) in the Classical Athenian polis. Six models are proposed: the religious city, the consumer-stamental city, the modern city, the class city, the institutional city, and the philosophical-existential city; after that, the paper discusses some recent historiographical alternatives.
\end{abstract}

Keywords: Historiography - Models - Athens - Metics.

(6) Dizia Hegel na Razão na História: "Também o historiador corrente e mediano, que intenta e pretende conduzir-se apenas à maneira de inventariante, entregando-se somente ao que é dado, não é passivo no seu pensar; traz consigo as suas categorias e vê através delas o existente" (citado em Grespan 2004: 13). 


\section{Referências bibliográficas}

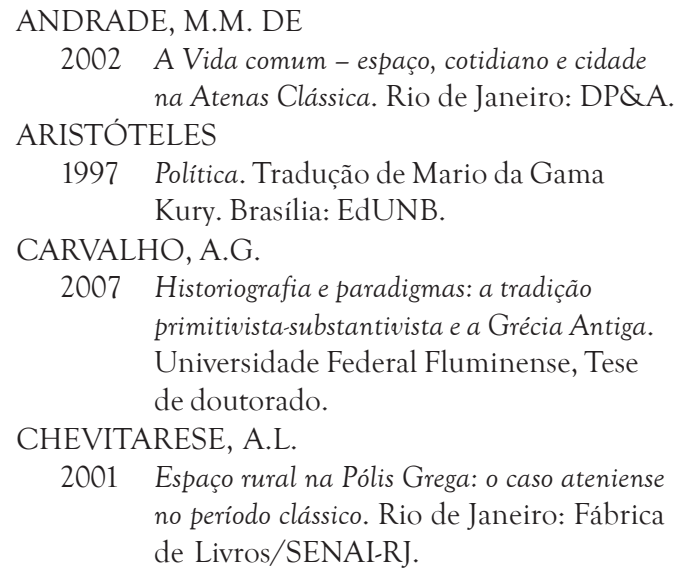

2002 A Vida comum - espaço, cotidiano e cidade na Atenas Clássica. Rio de Janeiro: DP\&A.

ARISTÓTELES

1997 Política. Tradução de Mario da Gama Kury. Brasília: EdUNB.

CARVALHO, A.G.

2007 Historiografia e paradigmas: a tradição primitivista-substantivista e a Grécia Antiga. Universidade Federal Fluminense, Tese de doutorado.

CHEVITARESE, A.L.

2001 Espaço rural na Pólis Grega: o caso ateniense no período clássico. Rio de Janeiro: Fábrica de Livros/SENAI-RJ.

CLERC, M.A.E.A.

1893 Les Métèques athéniens: étude sur la condition légale, la situation morale et le rôle social et économique des étrangers domiciliés à Athènes.

COHEN, E.E. Paris: Thorin \& fils.

2000 The Athenian Nation. Princeton: Princeton University Press.

FINLEY, M.I.

1985 Política no Mundo Antigo. Rio de Janeiro: Zahar.

1986 A Economia Antiga. 2a edição, Porto: Afrontamento.

FUSTEL DE COULANGES, N.D.

1995 A cidade antiga. 3a edição. São Paulo: Martins Fontes.

GARLAND, R.

1987 The Piraeus: from the fifty to the first century B.C. London: Duckworth.

GERNET, L.

1968 Anthropologie de la Grèce Ancienne. Paris: Maspero.

GLOTZ, G.

1980 A cidade grega. Rio de Janeiro: DIFEL.

GRESPAN, J.L.

2004 O lugar da História em tempos de crise. Revista de História, 151: 9-27.

GUARINELLO, N.L.

2003 Uma morfologia da História: as formas da História Antiga. Politeia, 3: 41-61.

2004 História científica, história contemporânea e história cotidiana. Revista Brasileira de História, 24 (48): 13-38.

HALL, J.M.

1998 Ethnic Identity in Greek Antiquity. Cambridge: Cambridge University Press.
HANSEN, M.H.

1974 The Sovereignty of the People's Court in Athens in the Fourth Century BC and the Public Action against Unconstitutional Proposals. Odense: Odense University Press.

1993 La démocratie athénienne à l'époque de Démosthène: structure, principes et idéologie. Paris: Les Belles Lettres.

1998 Polis and City-State: an ancient concept and its modern equivalent. Copenhagen: Munksgaard.

HANSEN, M.H.; NIELSEN, TH.H.

2004 An inventory of archaic and classical poleis. Oxford / New York: Oxford University Press.

HORDEN, P.; PURCELL, N.

2000 The Corrupting Sea: a study of Mediterranean history. Oxford/Massachusetts: Blackwell Publishers.

JOLY, F.D.

1999 Capitalismo e burocracia: economia e política nas Relações Agrárias da Antiguidade, de Max Weber. Revista de História, 140: 9-22.

LORAUX, N.

2005 La cité divisée: l'oubli dans la memoire d'Athènes. Paris: Éditions Payot \& Rivages.

MARX, K.

1977 Formações econômicas pré-capitalistas. São Paulo: Paz e Terra.

MEIER, CH.

1995 La naissance du politique. Paris: Gallimard. MEYER, E.

1955 El historiador y la Historia antigua: estúdios sobre la teoria de la Historia y la Historia economica y política de la Antigüedad. México/Buenos Aires: Fondo de Cultura Economica.

MILLETT, $\mathrm{P}$.

1998 Encounters in the Agora. In: Cartledge, P.; Millet, P.; von Reden, S. (Eds.)

Kosmos: essays in order, conflict, and community in classical Athens. Cambridge/ New York, Cambridge University Press: 203-28.

MOSSÉ, C.

1995 Politique et société en Grèce ancienne: le "modèle" athénien. Paris: Aubier.

MOSSÉ, C.; VIDAL-NAQUET, P.

1979 Clases y lucha de clases en la Grécia Antigua. Madrid: Akal. 
MURRAY, O.

1990 Cities of Reason. In: Murray, O.; Price, S. (Eds.). The Greek City: from Homer to Alexander. Oxford, Clarendon Press: 1-25.

OBER, J.

1996 The Athenian Revolution: essays on Ancient Greek democracy and political theory. Princeton: Princeton University Press.

OSBORNE, R.

2000 The demos and its divisions. In: Murray, O.; Price, S. (Eds.). The Grek City : from Homer to Alexander. Oxford, Clarendon Press: 265-93.

POLIGNAC, F. DE

1984 La naissance de la cité grecque: cultes, espace et société VIII'-VII siècles avant J.-C. Paris: La Découverte.

RICOEUR, P.

1990 Interpretação e Ideologias. Rio de Janeiro: Francisco Alves.

\section{ROSTOVTZEFF, $\mathrm{M}$.}

1973 História da Grécia. Rio de Janeiro: Zahar Editores.

ROY, J.

1998 The threat from the Piraeus. In: Cartledge, P.; Millet, P.; von Reden, S. (Eds.) Kosmos: essays in order, conflict, and community in classical Athens. Cambridge/ New York, Cambridge University Press: 191-202.

STE. CROIX, G.E.M. DE

1981 The Class Struggle in the Ancient Greek World: from the Archaic Age to he Arab Conquests. London: Duckworth.

TRABULSI, J.A.D.

2001 Uma cidade de participação controlada: a 'cidade grega' segundo os positivistas. In: Benoit, H.; Funari, P.P.A. (Orgs.) Ética e
Política no Mundo Antigo. Campinas, IFCH-Unicamp/FAPESP: 63-92.

UTCHENKO, S.

1984 Classes e estrutura de classes na sociedade escravista antiga. In: Pinsky, J. (Org.) Modos de produção na antiguidade. $2^{\text {a }}$ ed. Rio de Janeiro, Global Editora: 157-68.

VERNANT, J.P.

1972 As origens do pensamento grego. Rio de Janeiro: DIFEL.

VLASSOPOULOS, $\mathrm{K}$.

2007 Unthinking the Greek Polis: Ancient Greek History beyond the Eurocentrism. Cambridge: Cambridge University Press.

VON REDEN, S.

1995 The Piraeus - a world apart. Greece $\mathcal{E}$ Rome, 42 (1): 24-37.

WALLERSTEIN, I.

1974 The Modern World-System, vol. I: Capitalist Agriculture and the Origins of the European World-Economy in the Sixteenth Century. New York/London: Academic Press.

WEBER, M.

1999 Economia e Sociedade (2 volumes). Brasília/ São Paulo: EdUnB/Imprensa Oficial.

WHITEHEAD, D.

1977 The ideology of the Athenian Metic. Cambridge: The Cambridge Philological Society (Supplementary Volume no. 4).

WILL, E.

1954 Trois quarts de siècle de recherches sur l'économie grecque antique. Annales ESC, 9 (1): 7-22.

WOOD, E.M.

2003 Democracia contra capitalismo: a renovação do materialismo histórico. São Paulo: Boitempo Editorial. 